\title{
Application of On-board Data in Simulation Training Teaching of Vocational College: Taking the Major of Railway Communication Signals as an Example
}

\author{
Zhang Li \\ Liaoning Railway Vocational and Technical College, Jinzhou, 121000, China \\ 1048931300@qq.com
}

Keywords: on-board; train-control data; simulation training

\begin{abstract}
With the deepening reform of the modern vocational education, the proportion of simulation training in vocational education practice is increasing day by day. Taking the major of railway communication signal as an example, this paper studies the application of the on-board train control data in the simulation training of the higher vocational education, develops the simulation training task of on-board train control data, and discusses the application and development process of the on-board control data in the simulation training.
\end{abstract}

\section{Introduction}

The Ministry of education pointed out in the key points of the work on vocational education and continuing education in 2017 that deepen reform and innovation, stimulate the vitality of vocational education, and promote the integration of production and education, and cooperation between schools and enterprises. The development of vocational education is an important way to stimulate economic development, promote employment, improve people's livelihood and solve the "three rural issues". It is also a key link to ease the contradiction between labor supply and demand, so it must be placed in a more prominent position. Vocational education should take service as its objective and take employment as the guidance to promote the reform of education and teaching, implement the talent training mode of combining work with study, school enterprise cooperation and internship.

Practical teaching is a remarkable feature of vocational education, so we should strengthen the practical teaching in all aspects of education and teaching, emphasizes the training of practical ability, professional ability, occupation ability, pay attention to the basic role of application-oriented, skilled personnel training in practice teaching. In this way, the corresponding training course development and teaching reform are prominent in the development of vocational education. The development of vocational education is closely related to the development of the industry. Vocational education relies on the industry to train high-quality skilled personnel, and graduates should meet the requirements of the market and enterprises. However, relevant professional correspond to the railway industry as the representative of many industries in the field of teaching to the introduction of large and expensive training equipment, so the cultivation of students' occupation skill in the modern occupation education application simulation training device has become an effective way. Related specialized teaching of railway industry, as the representative of many industries in the field of teaching, can not bring large, expensive training equipment into college, so in the modern occupation education, the application of simulation training equipment becomes an effective way to cultivate students' occupation skills. Taking the major of railway communication signal as an example, this paper studies the application of the on-board train control data in the simulation training of the higher vocational education, develops the simulation training task of on-board train control data, and discusses the application and development process of the on-board control data in the simulation training. 


\section{The Necessity of Simulation Training Course in Modern Vocational Education}

At present, our country is in the period of economic restructuring and industrial upgrading, hundreds of millions of senior technicians and high-quality professional talents have become the active demand, which requires the modern occupation education system and teaching methods with more quality and efficiency to be supported. Simulation training system and simulation training course teaching could give full play to the advantages, not only to meet the requirements for improving teaching methods and teaching methods, but also to meet the business requirements of high skilled talents demand.

With the development of science and technology, simulation training has entered the practice teaching of vocational education in recent years. With the advantage of simulation, practicalness, scene, autonomy, safety and encouragement, the simulation training has been gradually recognized and developed continuously, and the proportion of practice teaching has increased year by year. But at the present, there is no systematic research on the simulation training course. Curriculum development generally adopts the "four stages" model of vocational ability module curriculum development, which is also aimed at strengthening the practice teaching.

The safety degree of railway transportation production is high and the management system is strict. Train control simulation training could enhance students' ability to adapt to future work, provide the real working environment, and cultivate students' good psychological quality to further improve students' ability to do practical work. At present, with the rapid development of high-speed railway, train control equipment has been widely used in the railway field. Most of our school students will work in the railway field after graduation, so in order to deepen the students' cognitive level on the train control equipment and improve daily maintenance skills of train control equipment, we use the train control simulation training room to have on-board control data training teaching, and train students on equipment maintenance skills, which saves the cost of arranging large numbers of students to visit the train control equipment at the railway site and ensures students operate the machine with their own hands. Through train control simulation training, students are familiar with the actual work of high-speed railway train control equipment before graduation, understand the actual situation of enterprises and experience enterprise culture, broaden their horizons. After graduation, students can work directly and they are usually welcomed by employers.

The construction and perfection of the on-board train control simulation training room and the advent of the big data era of on-board train control equipment contribute to the teaching development of equipment maintenance of automatic train control system, the core specialized course of railway communication signals in our college, become a diversified teaching model integrated with classroom teaching, multimedia demonstrations, on-site operations, situational teaching and other teaching methods. We use on-board train control simulation training room to train students and trainees in order to help students to master the maintenance of automatic train control system equipment, which is the importance content of combination of learning with working, and is also the development trend of the teaching of railway signal specialty. At the same time, it has expanded the employment scope of telecommunication signal graduates in high-speed railway and urban rail transit related column control equipment.

\section{Develop On-board Train Control Data Simulation Training Task}

Under the environment of accelerating the development of modern occupation education and with the construction of model school, the construction of on-board simulation training room will drive the teaching reform of train automatic control system equipment maintenance. How to apply the on-board train control data in the simulation training teaching of higher vocational education is the key point of the reform research. There is no precedent for the application of train control data in the simulation training teaching in higher vocational colleges for the major of railway communication signal in Liaoning Province. The big data era of the railway industry has arrived, 
and it will change the teaching mode of the relevant professional courses, and promote the application of on-board train control data in the simulation training teaching of higher vocational education.

\section{(1) Development ideas}

By analyzing the data of the on-board train control ATP and summarizing the rules, we obtain the development ideas of simulation training task of on-board train control.

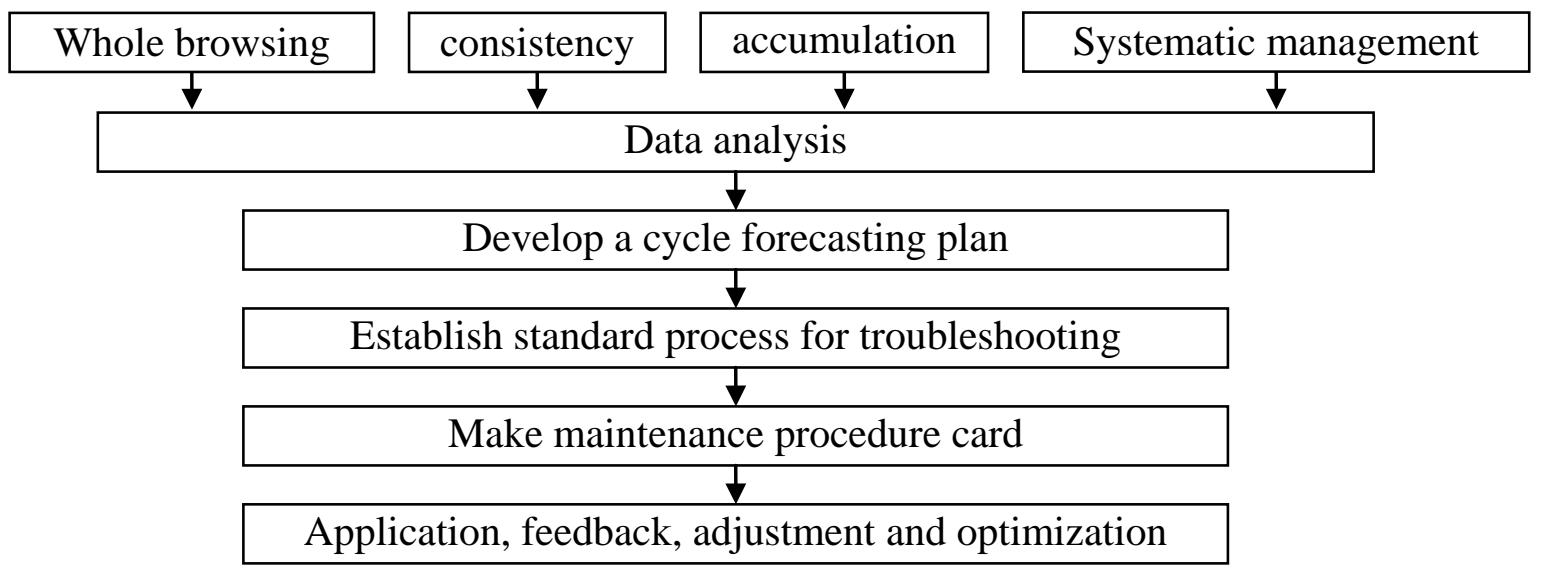

Fig. 1. Development ideas of simulation training task of on-board train control

The overall data browsing, means maximize the time span (1h) and examine the whole operation mode curve to make sure whether there is an abnormal deceleration, abnormal descent of model curve or parking, fault trigger point or transponder alarm information. Through the overall browsing, you can quickly find the general location of the fault point, and then focus on the data around the fault point, and carefully check the data of each part.

Data consistency, we should not only analyze the data of the fault point, but also check and analyze the data before and after the fault point. In particular, we should pay attention to the data analysis before the fault trigger point, and many faults are displayed after the trigger point, but the real trigger point of the fault is before that. For example, when the transponder is lost, although the fault trigger point is here, the cause of the actual fault triggering is in the front.

Accumulate data. Compare the data of the same type and the same fault point before and after fault treatment . Especially pay attention to the continuous fault in the same place, by comparing the data before and after, we can find common ground and the cause of the failure.

The systematic management of on-board ATP data is very important for the analysis and judgment of fault data. For repeated failures which are difficult to find out the cause, we could find common ground through the comparison, statistics, comprehensive analysis and judgment of multiple data, so as to find the real reason. Interference in the BTM antenna of train controlled on-board ATP device is discovered through a large amount of accumulated data and analysis and the comprehensive test, which plays a decisive role in improving the BTM antenna cable and reducing the failure rate.

By establishing a database of system failure analysis reports, we make careful fault cycle statistics for on-board ATP data, in addition, by adding seasonal factors and external environmental factors, we calculate the high cycle of failure, and on this basis, adjust and optimize equipment maintenance and repair schedule cycle. In this way, we can arrange the manpower and material resources reasonably, carry out the most efficient equipment maintenance with the least cost, improve the work efficiency, and avoid the fixed cycle overhaul of the whole system.

In order to master the damage reason of the onboard ATP device, we usually distinguish self-checking failure and reception failure in preventive maintenance or fault report, and collect the analysis data of failure time, fault area, fault cause and consequence by taking the carriage as a unit. To do so, on the one hand, we can do well prevention work for the safety of train controlled ATP, on the other hand, we can accumulate experience of data failure analysis. Of course, it is also important to continue to complete the management of the hidden trouble and fault emergency mechanism for train-controlled on-board ATP in the later stage of the study. 


\section{(2) Development process}

Compared with the traditional signal devices, train-controlled on-board equipment has great difference. The system of train-controlled on-board equipment in high speed railway train has a higher integration, software and hardware are more complex than the traditional signal equipment, its fault is difficult to find and usually happen without any warning. Therefore, the traditional detection methods are unable to meet the needs of fault detection. The on-board equipment of high-speed railway train has the fault prompt and fault code indication function. In combination with the actual maintenance requirements, on-board equipment is equipped with perfect portable detection system and dynamic monitoring device (referred to as DMS), with functions of auxiliary maintenance, recording, downloading, analysis, recording and statistics. The relevant detection devices are installed in the corresponding cabinet and the information of the status of on-board equipment, the location of the transponder and the transmission characteristics of the track circuit are collected during the train operation. Through wireless method, the data is transmitted to the ground data center in real time, and the automatic collection and real-time analysis of the fault information are realized.

When the on-board equipment is put into use, the equipment suppliers will conduct the related training for on-site technical personnel and establish perfect maintenance system to ensure the timely download records related to fault diagnosis for analyzing each fault occurred in operation and confirming whether there is related security issues in improving system availability. Considering the complexity and diversity of on-board equipment fault and in order to ensure the accuracy of fault analysis and positioning in on-board equipment, on the one hand, we have gradually formed a system, including maintenance area, maintainer of on-board equipment workstation, technical backbone of electricity section, after-sales service personnel of on-board equipment supplier, hierarchical responsibility system of technologist, and 24-hour service. When the system fault occurs, workstation maintainer should download and analyze the relevant records immediately, for the common fault, give a call to after-sales service staff of equipment suppliers, then report to electricity section and take appropriate measures after approval; for uncommon fault, workstation maintainer provide data to technical experts of equipment suppliers for analysis, then experts provide specific response measures and solutions, finally workstation maintainer implement. On the other hand, combined with the fault happened at the scene, the supplier of on-board equipment summed up the corresponding fault handling manual, including all kinds of typical fault features, fault analysis, fault measures, as a basis for field analysis and troubleshooting. All of these ensure that the analysis and measures of the on-site failure can be completed in the first time and ensure the reliability and safety in the operation of the on-board equipment.

We use transponder message data of on-board train control simulation training room to simulate operation of the automatic control equipment when the train runs at the railway site. The training project of transponder message can not only train related technical workers working in the railway field, but also simulate the equipment operation, testing, troubleshooting and problem solving under normal operating conditions, which contribute to completing staff practical skills training without affecting the normal operation of the railway.

In the course of data simulation training, the tasks are to be completed in the data simulation scenario. The teaching organization form simulates the enterprise to discuss the real work cases. We use a variety of teaching strategies and teaching methods, including role play, case analysis, group discussion, and team work to attract students to join the teaching activities.

Through the informatization mode, such as data simulation training, we use modern information technology in teaching to strengthen teaching practice, pertinence and effectiveness, stimulate students' interest in learning, and improve the quality of teaching.

Combined with the actual situation of our university that most of the graduates entered the Shenyang railway bureau, project development of the data simulation training simulates the work task of Shenyang railway bureau.

With integrated train control system, taking train-control data simulation training project development as the main line, based on the field investigation, combining the development of 
teaching material and the construction of resource storehouse, we carry out a comprehensive study of on-board train control data and establish on-board train-control data training model for vocational students of railway communication and signal.

Pay attention to urban rail transit (CBTC) system. With the increasing pressure of urban traffic, the effect of urban rail transit on relieving traffic pressure is becoming more and more obvious. All middle and large cities are building rail transportation. Therefore, the demand for talents of urban rail transportation will increase considerably in the coming decades. It is very important for students of urban rail control to familiar with current and future track developments and get related training before practical working.

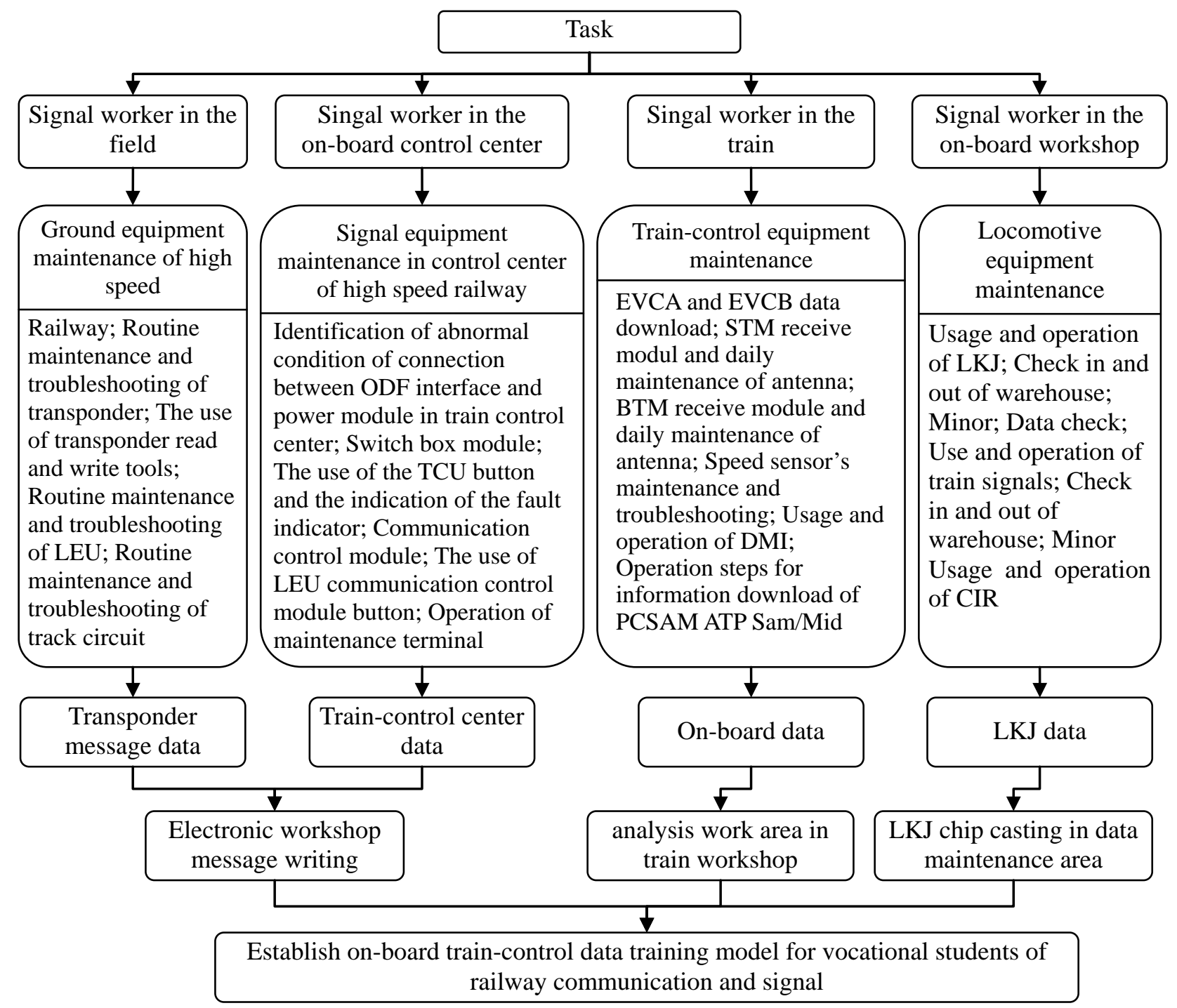

Fig. 2. Application development process of on-board train-control data in simulation training

\section{Conclusion}

When the system fault occurs, workstation maintainer should download and analyze the relevant records immediately. For the common fault, maintainers report to electricity section and take appropriate measures after approval; for uncommon fault, maintainer download relevant records and provide the data to technical experts of equipment suppliers for analysis, then experts provide specific response measures and solutions, finally maintainer implement. On the other hand, combined with the fault happened at the scene, the supplier of on-board equipment summed up the corresponding fault handling manual, including all kinds of typical fault features, fault analysis, fault measures, as a basis for field analysis and troubleshooting. All of these ensure that the analysis 
and measures of the on-site failure can be completed in the first time and ensure the reliability and safety in the operation of the on-board equipment.

With more and more high-speed trains, the demand for train system safety will be higher and higher. Only by understanding and mastering the analysis method of common faults of onboard equipment data analysis software 200C-ATP, we can seize the key point of the fault accurately, effectively reduce the fault delay to ensure the safe operation.

The above is the experience which the author summed up in the development and teaching of on-board train control data simulation training. With the development of vocational education and the deepening of the reform, we will work out a more capable and professional data simulation training which is more in line with the needs of the market to promote the orientation of higher vocational talents training more accurate and efficient.

\section{References}

[1] Ma Jianmei. Study on Employment-oriented Vocational Curriculum Development [J]. Liaoning Higher Vocational Technical Institute Journal, 2014(4): 60-61.

[2] Zhang Li.Development and Teaching Reform of Modern Vocational Education Simulation Training Curriculum-- Taking the Major of Railway Communication Signals as an Example [J]. Liaoning Higher Vocational Technical Institute Journal, 2015(1): 75-77.

[3] Sun Binbin. Application of Virtual Simulation Technology in Practice Teaching of Vocational Education [J]. Liaoning Higher Vocational Technical Institute Journal, 2014 (4): 68-70.

[4] A platoon-based traffic signal timing algorithm for major-minor intersection types[J]. Yi Jiang, Shuo Li, Daniel E. Shamo. Transportation Research Part B . 2005 (7).

[5] An introduction to multisensor data fusion. HallD L,Llinas J. Proceedings of the IEEE . 2004.

[6] SJA1000 stand-alone CAN controller product specification. PHILIPS Corporation. 2000. 